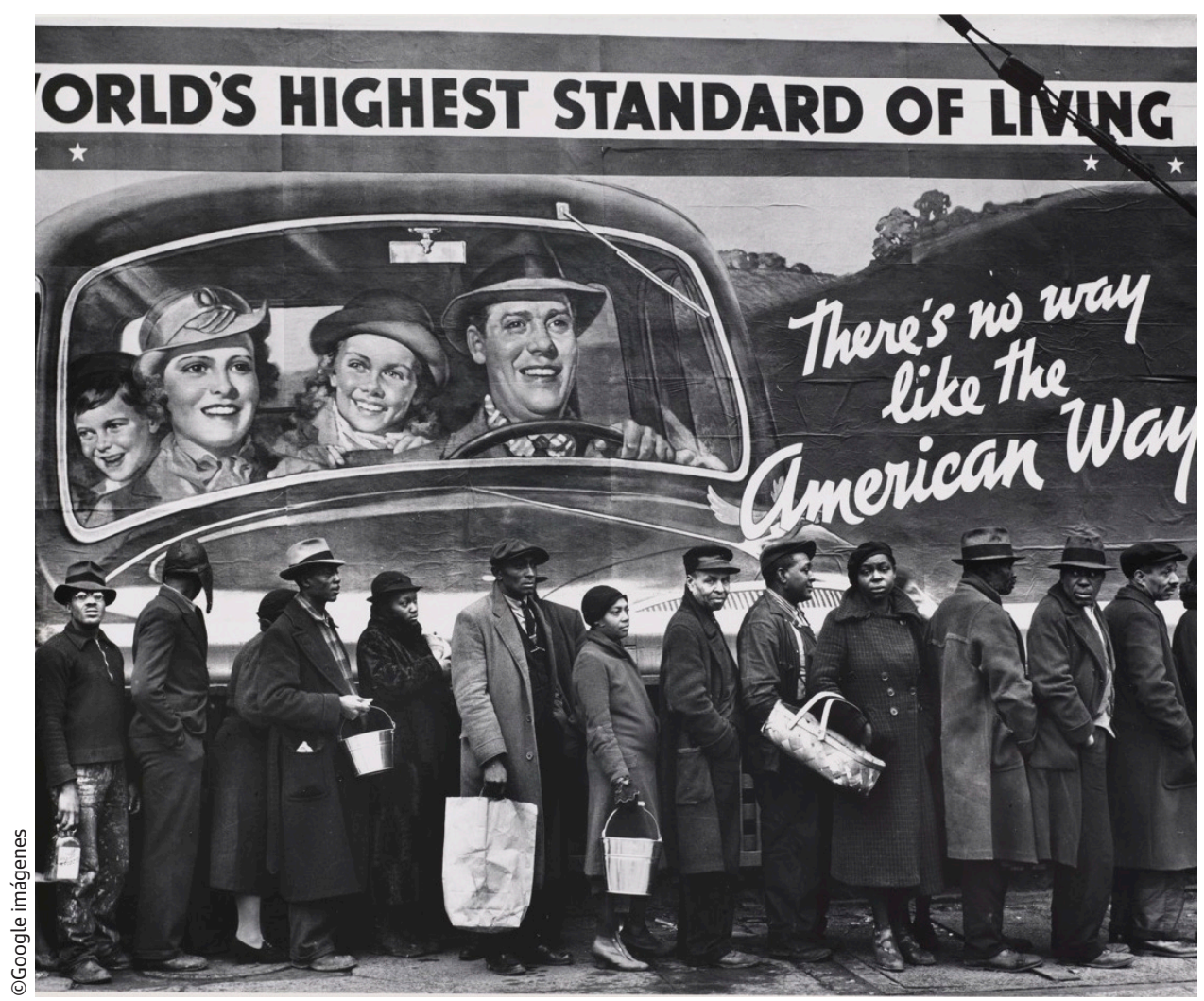

\title{
"MAD MEN", "LOS SOPRANO" Y EL "AMERICAN WAY OF LIFE". HISTORIA DEL CAPITAL EN DOS TIEMPOS
}

\author{
MAD MEN, THE SOPRANOS AND THE \\ AMERICAN WAY OF LIFE. THE HISTORY OF \\ CAPITAL IN TWO TIMES
}

Elisa Hernández Pérez / elisa.hdez88@gmail.com Jordi Revert Gomis / revert.jordi@gmail.com UNIVERSITAT DE VALÈNCIA 


\section{RESUMEN}

Don Draper (Mad Men, Matthew Weiner, AMC: 2007-2015) participa del nacimiento y consolidación de la sociedad de consumo sin ser consciente de la gran ficción que intenta creerse. Tony Soprano (The Sopranos, David Chase, HBO: 1999-2007) se agarra desesperadamente a los últimos restos de un ideal de superación y esfuerzo que no solo está agotado sino que nunca fue verdaderamente coherente. Este texto realiza un análisis textual, sociológico y discursivo comparativo de ambas figuras en cuanto representativas de la evolución del discurso capitalista en la segunda mitad del siglo XX, es decir, la artificialidad del discurso hegemónico de búsqueda de la felicidad como uno de los grandes mitos del neoliberalismo norteamericano de postguerra.

PALABRAS CLAVE

Series de televisión, American way of life, Capitalismo, Sociedad de consumo, análisis discursivo

\section{ABSTRACT}

Don Draper (Mad Men, Matthew Weiner, AMC: 2007-2015) actively colaborates in the birth and consolidation of a model of consumer society without realizing the enormous lie he is telling himself. Tony Soprano (The Sopranos, David Chase, HBO: 1999-2007) desperately grasps the wreckage of that ideal image of effort and self-improvement which is not only disappearing but was actually never coherent or real. This article does a comparative textual, sociological, and discursive analysis these two characters as a representation of the evolution of the discourse of capitalism in the second half of the 20th century, that is, the artificiality of the hegemonic discourse of "pursuit of happiness" as the main myth in post-war North American neoliberalism.

KEYWORDS

Television series, american way of life, capitalism, consumer society, discourse analysis

Recibido: 15 de junio de 2015

Aceptado: 10 de enero de 2016 


\section{INTRODUCCIÓN}

Desde el final de la II Guerra Mundial y hasta la década de los 70, Estados Unidos vivió lo que se ha venido a llamar "la época dorada del capitalismo": el país tuvo un enorme crecimiento del PIB y la producción, lo que se tradujo en una progresiva consolidación de la clase media. Por supuesto durante ese mismo periodo se produjeron sucesivas recesiones de tipo cíclico que culminarían con la crisis del petróleo de 1973 (originada, recordemos, por un conflicto político). El incremento del precio del crudo provocó que los países dependientes de este sufrieran enormes inflaciones y un descenso de su capacidad productora. A esto, hemos de sumar la caída del keynesianismo, cuyo énfasis en la creación de políticas y entidades de control fiscal y gasto gubernamental había dominado la economía occidental durante las décadas de los 50 y los 60. La debacle de Vietnam y las inflaciones generalizadas de los años 70 y 80 llevaron a un auge del monetarismo durante la presidencia de Ronald Reagan: la desregulación fiscal y la reducción de la intervención gubernamental en los movimientos del capital, llevando a lo que hasta hoy asociamos al neoliberalismo y la derecha norteamericana (tales como bajada general de impuestos, reducción al mínimo del gasto estatal y fomento del sector privado).

Como sabemos, la próspera postguerra norteamericana conlleva la instauración definitiva de un mito y modelo de individuo y sociedad cuyo discurso, a pesar de esta evolución histórico-económica (explicada de manera escueta en el párrafo anterior), sigue enormemente presente hasta la actualidad. Entrando finalmente en materia: ¿qué es, pues, la sociedad de consumo y qué implica para los individuos que viven en ella?

En los años 70 el teórico francés Jean Baudrillard establece que la sociedad de consumo es aquella en la que el consumo es su propia mitología, la trascendencia de su época, la manera en que dicha sociedad se piensa a sí misma (1974). Zygmunt Bauman, a su vez, explica que a nivel histórico y sociológico el consumo siempre ha sido una de las actividades fundamentales del ser humano en cuanto ciclo ingerir-desechar (2007B: 43), pero, y aquí coincide con Baudrillard, distingue "consumo" y "consumismo", empleando el segundo término para señalar una sociedad en que el consumo se convierte en el motor que dirige todos los movimientos de la misma, el propósito único en la existencia de sus miembros (2007B: 44). Para Bauman, pues, vivimos en una sociedad consumista en tanto que todo individuo no es sólo consumidor sino que al mismo tiempo es objetivizado continuamente para ser presentado al mundo como producto, hasta el punto en que la propia vida diaria y cotidiana asemeja cada vez más su funcionamiento al del mercado (2007B:17-18). Volviendo de nuevo a Baudrillard, el consumo adquiere una lógica social cuando los objetos pasan a adquirirse no por su valor de uso sino por su valor como signos, pero, además, signos que no se organizan como un código sino como status social: autoinserción en el orden social mediante el consumo (1974: 92-93), lo que significaría la creación personal de nuestra posición o lugar en la sociedad, es decir, nuestra identidad. Al fin y al cabo, el sujeto es una construcción discursiva y artificial, y que, como nos dice Clément Rosset recurriendo a ideas de Deleuze y su trabajo con Guattari (además de ciertos aspectos del último Foucault)ㄹ, el yo profundo e interior es simplemente el "fantasma" (también en el sentido en que nos ronda continuamente) del yo social, aquello que nos impide constatar la inutilidad y futilidad de la búsqueda de una identidad personal y estable, pues ésta es inexistente (2007: 31).

Pero recordemos que aun así la modernidad se basa precisamente en la ilusión de existencia de este yo racional, fijo e identificable, promoviendo una "compulsiva autodeterminación"

\footnotetext{
1 Clément Rosset cita específicamente El anti-edipo (Deleuze y Guattari, 1985), pero muchas de las cuestiones que trata remiten también a los últimos cursos de Michel Foucault en el Collège de France. Un claro ejemplo es Hermenéutica del sujeto, dictado de enero a marzo de 1982, donde se describe la subjetividad en época antigua en relación a una serie de prácticas de uno mismo sobre sí, confirmando así la historización de dicha subjetividad y haciéndonos reflexionar sobre artificialidad del yo también en época moderna.
} 
(Bauman, 2007A: 37), buscarse continuamente a uno mismo, tratar de establecer para uno mismo esta identidad única. Hasta aproximadamente los años 70 es posible hablar de un capitalismo pesado, estable, que Bauman identifica con el modelo del fordismo y su tendencia al orden (2007A: 63) y que podemos asociar también a esa empresa o institución predecible y con intenciones a largo plazo de la que habla Richard Sennet al tratar la necesidad humana de "generar un relato de vida" (2006: 12) (que no es otra cosa que la misma obsesión con la identidad) para el que hace falta un contexto firme y constante.

Sin embargo, la modernidad líquida y el capitalismo ligero o liviano, retomando la terminología establecida por Bauman (2007A), ofrecen precisamente todo lo contrario: incertidumbre sobre el futuro, inseguridad y dudas continuas, con un fomento de valores en realidad negativos como la adaptabilidad, la disponibilidad continua al movimiento y la falta de compromiso. Como veremos al tratar los personajes objeto de análisis de este trabajo, esto conlleva una dificultad cada vez mayor de establecer relaciones personales, una estigmatización de la dependencia (tanto emocional como económica) y la ausencia de sentimientos de pertenencia o comunidad.

Ante un entorno que poco a poco percibimos como más volátil, incierto y hostil, en cierta manera la reacción lógica está precisamente en insistir en los intentos de buscar y establecer un yo estable como medio para combatir la ansiedad. Así es como esta tarea, la autodeterminación, deviene una carga individual y personal, y no conseguirlo se percibe como un fracaso, haciendo que más que un proyecto de vida, esta obligación de autoafirmación del sujeto sea "una condena a trabajos forzados" (Bauman, 2007B: 151). Al fin y al cabo, e insistimos una vez más, la existencia de la identidad como algo fijo o estable es imposible, no existe, pero es precisamente este "fetichismo de la subjetividad" -que es lo mismo que Rosset llamaba la ilusión de la identidad personal- lo que oculta de hecho la mercantilización de la vida cotidiana y el deterioro social que ésta conlleva (Bauman, 2007B: 28): compe- titividad y egoísmo como las principales características de un contexto conformado por individuos cada vez más replegados en sí mismos.

En la -por llamarla de alguna manera- mitología norteamericana, todas estas ficciones sobre la construcción de una individualidad propia y única se ven ocultas por una serie de mitos propios que persisten en ellas y ayudan a su perpetuidad: el American way of life. Éste se basa fundamentalmente en el llamado sueño americano, que hunde sus raíces en la propia historia y configuración de Estados Unidos como Estado-nación (primero como colonia liberada y luego en la conquista del Oeste) y se caracteriza por la convicción de que cualquier ciudadano, gracias al esfuerzo y trabajo individual puede alcanzar la riqueza y el éxito personal por (y para) sí: el self-made man, es decir, el hombre hecho a sí mismo.

Son precisamente las consecuencias de este utópico e irreal modelo de subjetividad las que trataremos de señalar en Don Draper y Tony Soprano, a partir de la concepción de que tienen estos mitos irremediablemente interiorizados y naturalizados. Ambos personajes se convertirían así en la representación de la frustración provocada por la sociedad de consumo en dos momentos muy diferentes de la historia del capitalismo norteamericano del siglo XX. El primero surge como rostro y vector de esa sociedad de consumo a cuya forja asistimos a lo largo de Mad Men (Matthew Weiner, AMC: 2007-2015), al tiempo que se articula como ese fantasma del yo social que constata la imposibilidad de una identidad propia en esa idealizada década de los 60 en que se ambienta la serie. El segundo, protagonista de Los Soprano (The Sopranos, David Chase, HBO: 1999-2007), lo es también la decadencia del sueño espectacular del capitalismo financiero y posindustrial de los primeros años del siglo XXI, nos lleva a través de su resaca y confirma la vigencia del problema identitario.

Ambas series, como gran cantidad de la ficción norteamericana de los últimos años, han producido gran cantidad de literatura en relación a lo problemático y antiheroico de estos 
personajes -entre otros muchos temas-2. En línea con muchos de estos trabajos pero tratando de ir un paso más allá, la intención de este artículo es realizar un análisis textual y discursivo para establecer los paralelismos existentes entre ambos personajes como representantes perfectos de la historia económico-social de la segunda mitad del siglo XX, un relato en el que se desvanecen los espejismos del American way of life y el hombre hecho a sí mismo. Con este estudio pretendemos tratar de definir cómo la concepción de la subjetividad en el complejo contexto contemporáneo queda reflejado en las producciones culturales que la acompañan, considerando pues que las series de televisión dramáticas son sin duda un espejo en el que la audiencia puede mirarse, reconocerse e incluso comprenderse un poco mejor.

\section{DON DRAPER. PUBLICIDAD Y CAPITALISMO: UNA HISTORIA DE AMOR}

Dos definiciones de felicidad. En el primer capítulo de la primera temporada de $M a d \mathrm{Men}, E l$ humo ciega tus ojos (Smoke Gets in Your Eyes, \#1x01, Alan Taylor: 2008), Don Draper (Jon Hamm) busca convencer a Lee Garner Jr. (Darren Pettie) del eslogan que ha ideado para su marca de tabaco. En un momento dado, culmina su discurso como sigue:

\begin{abstract}
"La publicidad se basa en una cosa: la felicidad. ¿Y sabe lo que es la felicidad? La felicidad es el olor de un coche nuevo, es librarse de las ataduras del miedo, es una valla a un lado de la carretera que te confirma que lo que estás haciendo lo estás haciendo bien, que estás bien" 34 .
\end{abstract}

Muchos capítulos después, al final de la quinta temporada de la serie -en Comisiones y honorarios (Commissions and Fees, \#12x05, Christopher Manley: 2012) Don parece rematar esa definición de manera contundente:

“¿Qué es la felicidad? La felicidad es el momento anterior al momento en que necesitas más felicidad"5.
Ambas definiciones centran una esencia que lo es por partida doble. Por un lado, esencia del personaje que las dicta, anclado a un mundo de los deseos que lo define. Por el otro, de una sociedad de consumo que ayuda a construir en el seno de ese grupo de publicitarios de vidas, fruiciones y decepciones redundantes.

La conclusión es que Don Draper es la quintaesencia de ese sistema consumista llamado a construir el mundo del futuro, los primeros pasos que llevarán a una industria armada en torno a la sobreproducción de estímulos. En ese mundo, la felicidad es esa quimera que, en palabras de Baudrillard, "se halla más lejos aún de toda 'fiesta' o exaltación colectiva, puesto que alimentada por una exigencia igualitaria, se fundamenta en los principios individualistas" (Baudrillard, 1974: 78). Lo que de nuevo nos lleva a Don Draper: la búsqueda del protagonista de Mad Men se cimenta en el individualismo inculcado a través del mito del self-made man norteamericano. Don es un hombre sin pasado, que de he-

2 Sobre la llamada "televisión de calidad" en general, recomendamos el clásico de Robert Thompson (1997), así como la actualización del término en el libro editado por Janet McCabe y Kim Akass (2007). Igualmente son de gran relevancia los trabajos de Jason Mittell, sobre todo su reciente Complex TV: The Poetics of Contemporary Television Storytelling (2015), que de hecho incluye un capítulo dedicado al concepto de "personaje" en las series de televisión de la última década, haciendo referencia a cómo tanto Don como Tony representan el "sueño americano" (sin entrar en más detalle sobre el modo o las implicaciones de esta representación). De un modo similar, Christopher Bigsby analiza una enorme cantidad de series recientes en Viewing America. Twenty-First-Century Television Drama (2013) tratando de señalar la contradicción entre la imagen o narrativa "oficial" de América y el discurso subyacente sobre el fracaso (o no) de sus valores -la libertad, la familia, la comunidad-que podemos detectar en algunas de estas series, que el autor denomina como un lapso existente entre el ideal y la experiencia en su capítulo dedicado a Mad Men (2013: 403). En nuestro país, por supuesto, es indispensable mencionar los trabajos de la profesora Concepción Cascajosa $(2005,2007)$.

3 Salvo que se indique lo contrario, los diálogos citados han sido traducidos directamente de la versión original en inglés por los autores del texto.

4 "Advertising is based on one thing: happiness. And do you know what happiness is? Happiness is the smell of a new car. It's freedom from fear. It's a billboard on the side of a road that screams with reassurance that whatever you're doing is OK. You are OK."

5 "What is happiness? It's a moment before you need more happiness." 
cho robó la identidad de otro hombre durante la Guerra de Corea para recomenzar su vida desde cero. Rehúye -al menos durante gran parte de la serie- toda conexión con su vida anterior y abraza una profesión y estilo de vida en los que prima la inmediatez, el presente efímero consagrado un segundo tras otro a la ilusión de satisfacción. Como señala Óscar Brox, "el mundo de la publicidad es lo más cercano a una educación sentimental para Don, un patio de recreo en el que su intuición se mezcla con los vicios y las virtudes de la sociedad. Allí donde triunfan las apariencias, Don se erige en su mejor producto" (Brox, 2012). Por tanto, Don Draper es al tiempo producto y demiurgo en esa sociedad de consumo, creador y signo en sí mismo, por supuesto, intercambiable, canjeable, desechable.

Otra cosa es lo que subyace bajo esa construcción. Los personajes de Mad Men, y muy especialmente su protagonista, adolecen de una infelicidad de la que nunca consiguen escapar. Don huye del vacío con el alcohol y constantes aventuras extra maritales. En Betty se proyecta un retrato de la mujer de clase media-alta, aburrida y de sueños ya desechos, el mismo que Sam Mendes articulara sobre la Kate Winslet de Revolutionary Road (2008) vía la novela de Richard Yates. En realidad, casi todos los personajes de Mad Men componen una galería representativa de ese doble filo de la sociedad de consumo: la apariencia esplendorosa vestida de caros trajes y la incapacidad de ser feliz bajo todo eso. Los títulos de crédito de la serie creada por Matthew Weiner son explícitos a ese respecto: una silueta trajeada cayendo entre un sinfín de imágenes fantasmagóricas, rostros y cuerpos de mujeres y bebidas plasmados inanemente sobre lo que parece componerse como un edificio cualquiera del skyline de Manhattan. ¿Qué hay al final? El eterno retorno a ese sillón de publicitario que vuelve a encubrir las miserias personales con el ilusionismo de las marcas, los discursos de la seducción que los consumidores están esperando, pues estos desean ser seducidos. El acontecimiento del mito baudrillariano, creado en los despachos de Madison Avenue y aceptado en las tiendas y locales de América, es el cemento invisible que compacta los cimientos de una sociedad basada en una promesa y en los estímulos que la mantienen reluciente. Todo hermosamente disfrazado bajo la lógica de la razón -nuestra marca es mejor por estos motivos- o de la sinrazón calculada -abandónese sin pensarlo a este producto y será feliz- que constituyen el mito más allá de lo verdadero y lo falso.

Para entender el espacio temporal en el que se consolida el mito capitalista, bien podríamos recurrir a dos películas que se ubican respectivamente en el momento fundacional y en el de su apogeo. La primera es Pozo de ambición (There Will Be Blood, Paul Thomas Anderson, 2007), drama de época ubicado en los Estados Unidos de principio del siglo XX y centrado en el papel de los primeros empresarios del petróleo, representados en el personaje de Daniel Plainview (Daniel Day-Lewis), quien construye desde la nada un imperio que deja a su paso sangre y despojos de humanidad. La segunda es Revolutionary Road (Sam Mendes, 2007), adaptación de la novela de Richard Yates que se contextualiza en los años 50, momento en el que también se sitúa Mad Men y en el que el capitalismo adopta ya una forma sólida. En una de las escenas de la película de Mendes, cientos de hombres con traje, corbata, sombrero y maletín avanzan por el andén de una estación. Apenas existen diferencias entre ellos: similares colores grises, idénticos movimientos mecánicos ejecutados con monotonía. La imagen representa la perfecta evolución alcanzada por el sueño capitalista: el mito del individuo hecho a sí mismo, dueño de su propia suerte que se concentra en Daniel Plainview y su ambición por seguir ampliando su imperio, acaba derivando en cientos de individuos cuya identidad ha quedado diluida en una masa homogénea, allí donde solo tiene cabida la ilusión de la identidad personal de la que hablaba Rosset. La ambición del individuo, que avanza irrefrenable cobrándose víctimas, se disfraza de honesta ilusión colectiva: recibir un aumento de sueldo, ascender de piso y de cargo en la empresa, comprarse un coche mejor, una casa mejor, etc. 
En la película de Sam Mendes, Frank Wheeler (Leonardo DiCaprio) abandona la romántica de idea de ir a vivir a París con su esposa (Kate Winslet) cuando esta se queda embarazada y él recibe un ascenso. $Y$ este se produce acorde a la estructura vertical del capitalismo: subir de piso implica una ganancia de poder adquisitivo y avance en la escalera social. En esa progresión, el individuo acepta la lógica del sistema y su discurso, en tanto que se compromete -o aprende a comprometerse- con un sueño que a priori no es el suyo, este es, continuar con un trabajo que no le hace feliz, que no le resulta gratificante pero en el que está dispuesto a perpetuarse a cambio de cada vez más dinero. El que era en origen su sueño -ir a París, pasar un año escribiendo- acaba siendo forzosamente empujado al exterior de ese discurso, a la zona de lo irracional, lo absurdo y lo inmaduro, ya que -teóricamente- nada tiene que ver con lo productivo. Ahí es donde entran, una vez más, la publicidad y Don Draper. Ellos forjan la sintaxis llamada a convertir esa gris realidad en un mundo de infinitos atractivos, en el que el rito y el acontecimiento convierten el más vulgar objeto en producto deseado por todos -o, como mínimo, por todos aquellos que conforman el público objetivo que debe desearlo-. Pero todo eso forma parte del espectáculo debordiano, destinado a encubrir una lógica superior y perniciosa.

El capitalismo se validaba positivamente en esa sociedad de consumo en la que los publicitarios seducían y los consumidores se dejaban seducir. También en la promesa del sueño americano, íntimamente vinculado a la anterior. Pero una vez los años más felices de ese vínculo casi religioso han quedado atrás, el individuo cada vez encuentra más dificultades para seguir creyendo. Es entonces cuando el espectáculo se torna simulacro y potencia de forma agresiva la competitividad, a medida que el sistema también se vuelve más agresivo en sus hundimientos y resurrecciones. El capitalismo tiene que reinventarse en sus sucesivos colapsos si quiere sobrevivir como único paradigma legítimo -autolegitimado por su propio relato avasallador-, y lo mismo sucede con Don Draper. A lo largo de las siete temporadas de Mad Men, Don oscila entre el éxito y la decadencia, pasa de encontrarse en la cima del éxito a verse defenestrado en la propia agencia que ayudó a construir. En su autoficción, está condenado a dar vueltas mientras aspira a una felicidad que nunca puede alcanzar, pues esta es naturalmente irrealizable desde el momento en el que se articula en el mito.

El personaje encuentra su versión corregida y aumentada en el Tony Soprano (James Gandolfini) de Los Soprano. Si bien las diferencias entre uno y otro son notables, lo que les une no es insignificante: Don Draper es un constructor de esa realidad que se autovalida en su discurso, de hecho es parte activa de la construcción de ese discurso; Tony Soprano ha comprendido las fallas de ese sistema, el engaño implícito y ha preferido reproducir el modelo en los márgenes de este. Así, la mafia de Nueva Jersey es la expresión en chándal de ese capitalismo salvaje, una expresión puramente scorsesiana. Los mafiosos de David Chase en cambio optan por reproducir paralelamente las reglas del capitalismo, por erigirse directamente y mediante la violencia física como depredadores en el nivel superior de la cadena alimentaria. La mutación se hace necesaria porque ya ni siquiera resulta sostenible el discurso oficial que forjó ese sistema espectacular: el esfuerzo constante, la paciencia y el sacrificio tienen al final su recompensa. Ellos optan por tomar la recompensa a la fuerza, por lo que dejan de ser los espectadores pasivos para ser la parte interesada y poderosa. Y aun así, Tony Soprano se topa con la misma barrera que Don Draper: en su deslumbrante perfección, el rostro idealizado de ese capitalismo no contempla la sempiterna carencia emocional del triunfador, aquella en la que nunca podrá conseguir lo que desea porque lo que desea no deja de ser otro espejismo que se desvanece cuando lo acaricia con los dedos.

¿Qué sucede entonces cuando, insatisfechos y decepcionados, optamos por dar la espalda a esa lógica? Al final de la sexta temporada de $\mathrm{Mad}$ Men, Don Draper se obliga a ser honesto consigo mismo y su pasado. Es decir, decide abandonar 
toda apariencia y desnudarse emocionalmente incluso ante unos clientes. En El descenso (In Care Of, \#6x12, Matthew Weiner, AMC: 2013) seduce a los representantes de chocolate Hershey recurriendo al relato de su infancia, uno por supuesto ajustado a lo que ellos desean escuchar. Pero justo antes de que salgan por la puerta, Don comienza a relatar la verdadera historia de su niñez -la cual transcurrió en un prostíbulo- y acaba concluyendo en que no necesitan una campaña de publicidad. Así pues, el sujeto que hasta hace un momento vivía de la narrativa de lo deseable, de ese discurso de la sociedad de consumo fundamentado en la creación de ilusiones, ha optado con romper con esa lógica. Y los resultados son catastróficos. Antes Don renegaba de su pasado, lo reinventaba a su antojo y vivía persiguiendo sus deseos, venciendo al presente. Una actitud plenamente aceptable e incluso premiada por el paradigma de la sociedad de consumo. La transformación de su actitud supone, en cambio, un viraje inaceptable: confronta su pasado e incluso muestra a sus hijos el prostíbulo donde se crió. Un hombre que es todo pasado y que decide ser honesto consigo y con los demás se desalinea respecto a los intereses del sistema y se convierte en un agente imprevisible, incómodo. Las repercusiones no se hacen esperar: Don es suspendido en su trabajo indefinidamente y se sumerge en una depresión ahogada en alcohol y horas de televisión, ya al principio de la séptima temporada. Su regreso a la agencia no resulta menos doloroso, pues se ve obligado a empezar desde lo más bajo, incluso a las órdenes de la que un día fue su subordinada, Peggy Olson (Elisabeth Moss).

En la reconquista de su puesto como directivo de la empresa, el personaje ya ha saldado cuentas con su pasado y aprende a conciliar ese plano más sincero con el arte de las apariencias que una vez le hizo ser quien fue. En esa doble vertiente encuentra (o parece encontrar) al fin esa armonía largamente anhelada. Necesita participar del sistema espectacular, ser parte activa para sobrevivir, pero al mismo tiempo ha ganado distancia respecto a este. La conciencia adquiri- da del carácter evanescente de la felicidad, por fin, se traduce en una postura no impulsiva, en la que es posiblemente su versión más serena, puntuada con la epifanía de un número musical protagonizado por el ya difunto Bert Cooper (Robert Morse). A la espera del estreno en 2015 de los últimos siete capítulos de la serie, ese final contenido en Waterloo (\#7x07, Matthew Weiner, AMC: 2014) no debe ser interpretado como una mera conclusión feel-good. La canción que canta Cooper ante los alucinados ojos de Don es significativa y denota el estadio en el que se halla el personaje. Se trata de The best things in life are free, escrita para el musical de Broadway de 1927 Good News. El mensaje es, ni más ni menos, aquel que la sociedad de consumo y el capitalismo no pueden tolerar: las mejores cosas de la vida son gratis. Pero el número sucede solo en su cabeza, es una epifanía personalísima que por lo tanto escapa al control sistémico, y que le devuelve la sonrisa justo antes de entrar a su despacho, a tiempo para seguir diseñando los deseos y mitos del mundo de allá fuera. En la intimidad del episodio, Don ha encontrado la satisfacción asociada al valor inmaterial.

Sin embargo, los últimos episodios de la serie y, en particular, su conclusión, acabarán por demostrar que en realidad esa intimidad tampoco escapa a la trampa sistémica, que también se verá apoderada por esta. En la segunda mitad de la última temporada, los protagonistas de Mad Men ven como, tras la venta de la agencia a McCann-Erikson, su papel se va diluyendo en una jerarquía mayor. Pese a su acomodamiento económico, progresivamente pierden responsabilidades y reaccionan resignándose o distanciándose del mundo de la publicidad por vía de nuevas aventuras emocionales o profesionales. En el caso de Don Draper, su réplica ante esa nueva realidad es una vez más la de la fuga en busca de una felicidad que ya sabemos que no puede alcanzar. Si acaso solo su espejismo, una sensación de completitud con inevitable fecha de caducidad.

En el último episodio, Person to Person (\#7x14, Matthew Weiner, AMC: 2015), acaba 
uniéndose a un retiro espiritual del que tiene conocimiento a través de una vieja amiga. En una escena clave, uno de los miembros del grupo se sincera frente a los demás y habla de la imposibilidad de sentir la felicidad plena, de una carencia emocional en la que percibe que su vida apenas tiene efecto alguno sobre la de los demás. Tras su discurso rompe a llorar, y Don, identificado con sus palabras, lo abraza y llora desconsoladamente con él. Pocos segundos después, vemos al grupo meditando en posición de loto en el exterior. La secuencia culmina en un travelling sobre el rostro del personaje mientras emite un mantra. Una sonrisa se dibuja en su cara: parece, por fin, haber encontrado ese refugio de la realidad en el que hallar una completa serenidad, lejos del mundo de la publicidad, los bienes materiales y los despachos de las agencias. Acto seguido, no obstante se suceden las imágenes del anuncio de Coca Cola creado por McCann-Erickson en 1971. La pieza muestra a gente de todas las razas y culturas cantando una canción que reza el deseo de llevar el refresco más allá de cualquier frontera. El sentimiento de alegría comunal y la llamada al entendimiento intercultural domina cada plano, fagocitando por otra parte ese sentimiento de fuga y comunidad alternativa en el que se ha inscrito Don y también parte del espíritu hippy que ha dominado la década de los 60 y del que se ha hecho eco la serie. La contraposición entre el rostro del personaje y el anuncio revela que ya no es posible esa fuga, pues el capitalismo ha perfeccionado su forma hasta el punto de adueñarse de esa utopía: el sueño del aislamiento al que accede el protagonista de Mad Men no es, en definitiva, sino otra construcción más.

\section{TONY SOPRANO.}

\section{TARDOCAPITALISMO EN EL DIVÁN}

Tony Soprano podría parecernos, al igual que Don Draper, un hombre que lo tiene todo. Con unos cuarenta años al inicio de la serie, Tony Soprano es un alto jefe de la mafia italiana de New Jersey: vive en una enorme casa con jardín y piscina, tiene una esposa y ama de casa dedicada y dos hijos sanos, bastante dinero y una carrera en ascenso en lo que sin duda es un negocio de éxito. Una vez más, ¿dónde está el problema? Lo cierto es que ni él mismo lo comprende. Utilizando sus propias palabras: "Tengo el mundo cogido por las Pelotas y no puedo dejar de sentirme como un perdedor"6 (The Happy Wanderer, \#2x06, John Patterson, HBO: 2000).

El punto de partida de Los Soprano es, de hecho, la constatación de la necesidad inconsciente de Tony de comprender por qué sigue sintiendo ansiedad y frustración a pesar de ser un ejemplo perfecto de self-made man, es decir, de haber alcanzado la situación ideal según los modelos de vida de la sociedad norteamericana. Así, el episodio piloto (Pilot, \#1x01, David Chase, HBO: 1999) comienza con la primera sesión del protagonista con la que será su terapeuta a lo largo de varios años, incluyendo numerosos incidentes e incesantes idas y venidas entre ambos, la doctora Jennifer Melfi (Lorraine Bracco). Tony es referido a la psiquiatra por su vecino médico tras sufrir un desmayo repentino que no parece tener un origen físico sino mental. La cuestión es: ¿qué es la terapia de Tony Soprano sino un desesperado intento de definición de sí mismo que, por supuesto, fracasa? Las conversaciones con Melfi, al presentar los continuos intentos de introspección como auto-construcción de sí por parte del propio Tony, son el principal punto de interés para el análisis que se hará del personaje, ya que, como mencionamos en la introducción, pretendemos rastrear en estos dos ejemplos las consecuencias en los individuos de la obligación a crear nuestra propia identidad dentro de un contexto social consumista-capitalista.

Al final de su primera sesión, todavía en el episodio piloto, Tony se queja de que se le exija la definición de sí mismo a partir de la expresión de sus sentimientos, preguntándose “¿Qué fue de Gary Cooper? Un tipo fuerte y silencioso. Eso era un americano. No estaba en contacto con 6 "I got the world by the balls and I can't stop feeling like a
fuckin' loser" 
sus sentimientos. Simplemente hacía lo que tenía que hacer" ". Sin duda, Tony no se está refiriendo al Gary Cooper real, sino a su continua caracterización fílmica como modelo no sólo de masculinidad sino de independencia emocional. El film protagonizado por Cooper, Solo ante el peligro (High Noon, Fred Zinnemann, 1952) es mencionado en otras ocasiones en la serie e incluso aparece un clip en la televisión al final de la quinta temporada. No es anecdótico que Tony Soprano vea westerns -además de, por supuesto, films sobre mafiosos, mucho cine clásico y el Canal de Historia-, tratándose de uno de los géneros cinematográficos fundacionales del mito norteamericano por excelencia y destacando también el papel del séptimo arte en la consolidación de los valores de la sociedad. Por otra parte, la permanente necesidad de transmitir al mundo exterior nuestros sentimientos es una de las actividades que mejor ejemplifican la imposición de auto-definición, pues enlazaría directamente con esa obligación a decirse a sí mismo, de ponerse en discurso que Foucault identifica con la confesión cristiana y que implica la existencia de una verdad en nuestro interior, una especie de secreto oculto que hemos de sacar a la luz (2006: 61-63): el supuesto yo real. En una de las sesiones de terapia de House Arrest (\#2x11, Tim Van Patten, HBO: 2000) Tony confiesa que le parece que es "todo una serie de distracciones hasta que te mueres" 8 , insistiendo en la ya mencionada necesidad de que todos los individuos parecen tener de crear un relato de vida para sî mismos, de insertar todo hecho y acción en una historia universal con un fin, un sentido último, y la desesperación generada cuando se confirma que dicho relato es una ficción artificial y, en el fondo, inútil.

Volviendo de nuevo al episodio piloto, Tony se queja a la doctora Melfi de la pérdida de valores como el honor o la lealtad en las generaciones más jóvenes de mafiosos. Esta referencia continua al pasado -por ejemplo con la idealización y defensa de su padre fallecido que vemos en Tony a lo largo de toda la serie- indica una concepción fantasiosa de la etapa inmediatamente anterior de la historia norteamericana, aquel momento de crecimiento y "capitalismo dorado", los años $50 s$ y 60s. Como ya hemos visto con Don Draper, se trata de un modelo ideal falso: no es que ese paraíso se haya perdido y sea una tarea para el futuro intentar recuperarlo, sino que en realidad nunca existió.

La confirmación de esta inexistencia de ciertos valores también en generaciones previas a la de Tony Soprano la podemos encontrar en la que es una de las múltiples tramas que atraviesan la primera temporada de la serie: la confabulación para deshacerse de él por parte de su madre, Livia Soprano (Nancy Marchand) y su tío Corrado Junior (Dominic Chianese), llegando incluso a un fallido intento de asesinato orquestado por este en el episodio Isabella (\#1x12, Allen Coulter, HBO: 1999). Tony intenta racionalizar gran parte de sus acciones criminales a partir de la obligación de garantizar el bienestar de su familia como excusa, ya que la familia (tanto la carnal como la mafiosa) es el valor último y superior esgrimido por prácticamente todos los personajes de la serie. Sin embargo, la mencionada actitud de su madre y su tío demuestran que en realidad el rencor y sobre todo la ambición de poder individual se encuentran por encima de cualquier vínculo carnal o emocional.

En lo que al sueño americano se refiere, Tony dirá a la doctora Melfi: "¿Sabes que somos el único país donde la búsqueda de la felicidad está garantizada por escrito? ¿Puedes creértelo? Un puñado de puñeteros niñatos malcriados. ¿Dónde está mi felicidad, pues?"9, a lo que ella responde: "Es la búsqueda lo que está garantizado"10 (House Arrest, \#2x11). La referencia de Tony a la Declaración de Independencia de los Estados Unidos indica que verdaderamente cree que dada su

\footnotetext{
7 "Whatever happened to Gary Cooper? The strong, silent type. That was an American. He wasn't in touch with his feelings. He just did what he had to do."

8 "it's all a series of distractions "till you die."

9 "You know we're the only country where the pursuit of happiness is guaranteed in writing? Do you believe that? A bunch of fucking spoiled brats. Where's my happiness then?"

10 "It's the pursuit that's guaranteed."
} 
trayectoria y su posición actual, tendría que ser feliz, debería sentir esa armonía y tranquilidad de aquel que ha alcanzado a su destino, que posee todo aquello que cualquiera podría desear. Su frustración deriva, o eso cree él, de no saber qué es lo que le falta para llegar a la felicidad. La verdadera fuente de ansiedad de Tony, y la respuesta de la doctora Melfi es tremendamente lúcida en este sentido, es precisamente que se presente dicha placidez como un fin al que se puede llegar con años de esfuerzo y dedicación, es decir, que existe un punto de llegada para el que es necesaria una búsqueda. Esta concepción de la felicidad implica la posibilidad de un ser humano "completo", lo que es en realidad una artificialidad discursiva, una quimera: lo único que queda es la frustración de buscar sin encontrar. Dar vueltas en un laberinto sin saber que nunca llegaremos a la salida.

Otro aspecto tremendamente llamativo de la serie es que no nos resulta especialmente difícil poner en relación a Tony Soprano y la organización criminal que dirige y controla con la configuración y modelo de funcionamiento de muchas de las grandes empresas capitalistas contemporáneas. No existe por ejemplo ninguna consideración sobre las consecuencias a largo plazo -o en contextos no inmediatos a los implicados- de las acciones que realizan, solo importa obtener ganancias lo antes posible. No solo no les preocupa qué ocurrirá si llevan un negocio a la ruina o a algún conocido a la bancarrota -por poner algunos ejemplos de subtramas de la serie- sino que ni se interesan por conocerlas, siempre y cuando el dinero siga llegando a las manos de quien corresponda11.

Lo que más interesa a todos los personajes de Los Soprano es sacar el máximo beneficio económico de cada una de las situaciones en que se ven inmersos, pero también de todas las relaciones personales o de amistad que establecen. De hecho el propio Tony se da cuenta, a partir de que su mujer Carmela (Edie Falco) haga ciertos comentarios intencionadamente hirientes al respecto al inicio de la quinta temporada, de cómo aquellos a los que considera sus amigos actúan en realidad en beneficio propio y son amables con él solo porque es el jefe: se ríen exageradamente de sus chistes malos, alaban su aspecto físico, etc ${ }^{12}$. Esa idea de familia como comunidad cerrada y autosuficiente que está en boca de todos los personajes de la serie parece basarse una y otra vez en relaciones meramente económicas y de beneficio personal. Se busca la rentabilidad y eficiencia a cualquier coste, y toda pieza que no ayude o colabore en el correcto funcionamiento del engranaje como conjunto es eliminada, por mucho que sea familia. Recordemos que al final ni siquiera su querido sobrino Christopher Moltisanti (Michael Imperioli) sobrevive. Este personaje, a pesar de haber sido perdonado en numerosas ocasiones, termina siendo ahogado por el propio Tony tras sufrir ambos un accidente de tráfico en el episodio Kennedy and Heidi (\#6x18, Alan Taylor, HBO: 2007) ${ }^{13}$.

El último aspecto que nos gustaría destacar del personaje se relaciona directamente con lo anterior y es la imposibilidad que muestra de establecer verdaderas relaciones afectivas con las personas que le rodean, una característica que lo acerca sospechosamente a la sociopatía. La estigmatización de la dependencia emocional y la insistencia en la independencia absoluta que presenta Tony Soprano lo entroncan directamente en una tradición de antihéroes cínicos y despegados de la ficción -el detective del cine

11 En todo caso, no es este el momento de entrar en una comparación estadística o de intentar establecer las similitudes de los daños y sufrimientos provocados por el crimen organizado y por otras industrias aceptadas socialmente o legales, pero es sin duda una cuestión a tener en cuenta.

12 Aunque no tenga que ver directamente con Tony Soprano, la escena del entierro de Jackie Aprile, Jr. (Jason Cerbone) al final de la tercera temporada es especialmente desoladora en relación a esta cuestión. Jackie es el primogénito del antiguo jefe de la mafia de New Jersey, fallecido por cáncer al inicio de la serie. Al no tener ya familiares directos con poder e influencia, el velatorio de Jackie Jr. cuenta con pocos asistentes, muchos de los cuales están más pendientes de sus teléfonos (para organizar apuestas ilegales) que del evento en sí.

13 La lista de los familiares y amigos presuntamente queridos y apreciados por Tony que terminan asesinados (por encargo suyo o por sus propias manos) por ser problemáticos para el negocio es casi interminable. 
negro clásico, el solitario cowboy del western-, y que por supuesto han de relacionarse también con muchos de los estereotipos de las películas que él mismo suele ver, como indica su pequeña fijación con Gary Cooper. Lo interesante de Tony es que esta actitud no lo presenta como un modelo a seguir sino que se muestra como algo negativo y que forma parte de todo aquello que impide al personaje relacionarse afectivamente con los seres de su entorno. Pero lo más curioso de todo es que no deja de tener la necesidad de establecer vínculos emocionales a su alrededor. ¿Cómo queda resuelta esta pequeña contradicción en el caso de Tony? A través de los animales: algunas de las mayores explosiones de rabia y de impulsos incontrolados del personaje tienen lugar en directa relación con algunas de las mascotas que tiene a lo largo de los años.

Su primer desmayo por ataque de ansiedad se produce cuando descubre que los patos que habían utilizado su piscina como nido durante un tiempo finalmente aprenden a volar y desaparecen en el cielo. Tony, que parecía haber adoptado a los patitos como si fueran hijos suyos, nunca perderá la esperanza de verlos reaparecer y continúa comprando alimento para aves y guardándolo en el jardín -aunque termine utilizando el contenedor de la comida para esconder dinero negro-. Al inicio del episodio In Camelot (\#5x07, Steve Buscemi, HBO: 2004) se enfada sobremanera cuando su hermana le explica que el padre de ambos nunca llevó a su perro enfermo a vivir a una granja en el campo sino que se trata de un eufemismo empleado habitualmente para no tener que decir a los niños que el animal ha sido sacrificado. Incluso cuando poco después descubre que en realidad su padre había regalado el perro al hijo de su amante, Tony recrimina a su madre -durante una sesión con la doctora Melfi, ya que Livia Soprano fallece al inicio de la tercera temporada- que obligara a su padre a deshacerse del can, pero no a este sus múltiples infidelidades.

Pero sin duda el principal ejemplo de estas enfermizas relaciones que Tony establece con los animales en lugar de con los seres humanos que le rodean es el caballo de carreras Pie-OMy. El animal muere en el episodio Whoever did this (\#4x09, Tim Van Patten, HBO: 2002) porque Ralph Cifaretto (Joe Pantoliano) incendia las caballerizas para obtener el dinero del seguro del animal, cuya posesión comparten ambos personajes. Tony, ante la mínima sospecha de que Ralph es responsable, reacciona matándole en su propia casa. En el episodio University (\#3х06, Allen Coulter, HBO: 2001), este mismo personaje había asesinado a golpes a su novia embarazada ante Tony, quien, aunque reacciona agresivamente, lo hace con una intensidad mucho menor que en relación a Pie-O-My. En el episodio siguiente a la muerte de Ralph, titulado curiosamente The strong, silent type (\#4x10, Alan Taylor, HBO: 2002), Tony llora emotivamente en terapia sin tratar de disimularlo por el fallecimiento del caballo. El modelo supuestamente idealizado de independencia emocional y absoluta individualidad es entonces una imposibilidad, así como fuente de gran cantidad de problemas si uno intenta asumirlo como propio ${ }^{14}$.

A lo largo de la serie, son varias las ocasiones en que Tony Soprano se queja de la inutilidad de sus sesiones con la doctora Melfi, abandonándola y volviendo a ella continuamente en una especie de círculo vicioso. Sin querer entrar por supuesto en ningún tipo de debate sobre la utilidad o no de la terapia, sí que podemos establecer que Tony no parece encontrar lo que busca en ella: hay una mejora de algunos de sus síntomas, como los desmayos por ataque de ansiedad, pero no una solución a esta continua crisis personal, depresión y frustración que caracterizan al personaje. ¿Por qué? Porque en el fondo esta deriva de su incapacidad de amoldarse a un ideal, el del self-made man y el sueño americano del que, en teoría, es el ejemplo perfecto. El problema de Tony Soprano no es que no pueda soportar la realidad. Su problema es que no puede aguantar

14 Por supuesto, los problemas afectivos de Tony Soprano no solo tienen que ver con asumir este modelo, pero sin duda la existencia del mismo y la defensa que él mismo hace de esas características no ayudan a su resolución. 
el ideal de individuo que cierto modelo de sociedad le impone como un fin que en realidad es imposible de alcanzar. Esta es una carga demasiado pesada para cualquier individuo, obligado cada vez más a valerse por sí mismo y no depender de los demás no solo en su día a día sino incluso en la construcción de su propia identidad.

\section{CONCLUSIÓN. CAMINANDO ENTRE LAS RUINAS}

El análisis discursivo aplicado sobre Mad Men y Los Soprano y en particular sobre sus sendos protagonistas, Don Draper y Tony Soprano, deja de manifiesto el problemático estatus del sujeto dentro de la evolución del capitalismo: el de la imposibilidad de fijar su identidad en medio de un escenario que diluye al individuo en la búsqueda infructuosa de un deseo siempre insatisfecho. Mediante este mecanismo, la sociedad de consumo mantiene la promesa de una felicidad que es la fuerza motora de un sistema que ya vive de la ilusión de lo real, del simulacro y del valor del signo. Aun si Draper y Soprano son sujetos activos dentro de ese sistema, en tanto que colaboran en su consolidación o lo utilizan en su beneficio, no pueden escapar a las consecuencias emocionales de este y se hallan perdidos a la hora de definirse, un problema que no puede entenderse sin su estrecha vinculación con sus respectivos contextos. La correlación bien podría completarse con un tercer estadio que remitiría inevitablemente al desencanto y la toma de distancia que encontramos en buena parte del cine dedicado a retratar los efectos de la crisis global de 2008. Una buena muestra de ello sería la última secuencia de Mátalos suavemente (Killing Them Softly, Andrew Dominik, 2012), en la que el asesino a sueldo Jackie Cogan (Brad Pitt) reclama a su pagador (Richard Jenkins) el dinero que se le adeuda. Este le entrega solo una parte de lo acordado y se escuda en el argumento de que se hallan en crisis. Ante la insistencia del primero, apela al discurso de investidura de Barack Obama, que está siendo transmitido por televisión: la idea de que todos son uno, de que todos deben arrimar el hombro y solidarizarse como nación también vale para el gánster. La réplica de Cogan es demoledora: Estados Unidos no es un país, es un negocio, y en él estás por tu cuenta.

Queda, por tanto, evidenciado el discurso oficial y el descreimiento de su receptor, que ya no puede seguir confiando en este. Hemos alcanzado otra depresión del capitalismo, la mayor de todas, y en esa crisis que revela los enormes problemas estructurales del sistema este debe de reinventar su mensaje para sobrevivir. Si antes, conectando con Bauman, la sociedad de consumo insuflaba en el individuo la responsabilidad de sí mismo como consumidor (Bauman, 2007B: 127-128), como hombre o mujer llamado a conquistar éxitos y escalar socialmente, ahora la responsabilidad se transfiere hacia el sentimiento comunitario: consumir se presenta hoy como más necesario que nunca para garantizar la supervivencia del capitalismo como discurso hegemónico (sin aparente alternativa posible); al tiempo, esa nueva lógica tiene otra cara, por la que se hace inevitable recibir cada vez menos a cambio de igual o mayor esfuerzo. Sin embargo, Cogan ya no pertenece a esa comunidad que acepta el discurso oficial en sus derivas y mutaciones: como Tony Soprano ${ }^{15}$, vive en su exterioridad, pero a diferencia de él, que no entiende el origen de su frustración, ya camina entre las ruinas y el desencanto.

La gran divergencia respecto a Don y Tony es que no existe una ansiedad que cataliza ese tránsito desde la creencia de ser parte de esa lógica a adquirir cierta distancia con esta. Mátalos suavemente empieza, no por casualidad, con interferencias sonoras y visuales en un descampado lleno de basura. Es el contexto perfecto para el apocalipsis económico y moral, en el que no queda más que podredumbre y la imposibilidad de seguir creyendo. El recorrido adquiere perfecta coherencia e incluso cierta verticalidad a la in-

15 Curiosamente, el propio James Gandolfini interpreta uno de los personajes importantes de Mátalos suavemente, un asesino alcohólico y sumido en su decadencia que es incapaz de cumplir el trabajo que se le ha encomendado. 
versa del deseado ascenso capitalista, de los despachos de Madison Avenue a la casa de un capo de la mafia de Nueva Jersey, para terminar en un desolado paisaje de extrarradio. Un tránsito que define, desde la ficción altamente consciente de su tiempo, una historia económica del siglo $\mathrm{XX}$ que contempla la connivencia sistémica con el aparataje de la sociedad de consumo y habla de la disolución de la autoficción del self-made man, insuflada para seguir sosteniendo esa ilusión. Pero también, un relato que contempla las fluctuaciones del estado de ánimo de la contemporaneidad, bajo las atribuladas pieles de sus protagonistas. 


\section{BIBLIOGRAFÍA}

BAUDRILLARD, Jean. La sociedad de consumo. Sus mitos, sus estructuras, Plaza\&Janés, Barcelona, 1974.

BAUMAN, Zygmunt. Modernidad líquida, Fondo de Cultura Económica, Buenos Aires, 2007A.

BAUMAN, Zygmunt. Vida de consumo. Fondo de Cultura Económica, Madrid, 2007B.

BIGSBY, Christopher. Viewing America. Twenty-FirstCentury Television Drama. Cambridge University Press, NY, 2013.

BROX, Óscar. "El mundo según Don Draper". Miradas de cine, núm. 122, mayo de 2012. (http://miradas. net/2012/05/bloctv/mad-men.html consultado el 14 de diciembre de 2014).

CASCAJOSA, Concepción. Prime time: las mejores series de TV americanas: de CSI a Los Soprano. Madrid, Calamar Ediciones, 2005.

CASCAJOSA, Concepción. La caja lista: Televisión norteamericana de culto. Laertes, Barcelona, 2007.

DELEUZE, Gilles y GUATTARI, Felix. El anti-edipo: capitalismo y esquizofrenia, Paidós, Barcelona, 1985.

FOUCAULT, Michel. Hermenéutica del sujeto. Curso del Collège de France (1982), Akal, Madrid, 2005.

FOUCAULT, Michel. Historia de la sexualidad 1, la voluntad de saber. Madrid, Siglo XXI, Madrid, 2006.

GREENER, Richard y VERNEZZE, Peter. Los Soprano y la filosofía. Barcelona: Ariel, Barcelona, 2010.

Los Soprano: Internet Movie DataBase (http://www.imdb. com/title/tt0141842/, consultada el 22 de agosto de 2014).

MITTELL, Jason. Complex TV: The Poetics of Contemporary Television Storytelling, NYU Press, 2015.

REVERT, Jordi. "Los Soprano en cinco tiempos. O cómo aprendí a dejar de preocuparme y empezar a amar al gángster". L'Atalante, n011, enero-junio 2011, pp.5-11.

RÍOS, Iván de los et alii. Los Soprano forever, Errata Naturae, Madrid, 2009.

ROSSET, Clément. Lejos de mí. Ensayo sobre la identidad, Marbot Ediciones, Barcelona, 2007.

RUBIO, Agustín. "Carbon-copy de los años cuerdos. A propósito de Mad Men.", L'Atalante, n011, enero-junio 2011, pp.12-18.

SCOTT, Anthony Oliver. "The Death of Adulthood in American Culture". New York Times, 14 de septiembre de 2014 (http://www.nytimes.com/2014/09/14/magazine/ the-death-of-adulthood-in-american-culture.html consultado el 16 diciembre de 2014).

SENNET, Richard. La corrosión del carácter. Las consecuencias personales del trabajo en el nuevo capitalismo, Anagrama, Barcelona, 2000.
SENNET, Richard. La cultura del nuevo capitalismo, Anagrama, Barcelona, 2006.

SOUTH, James (ed). Mad Men and Philosophy, Blackwell, Londres, 2010.

THOMPSON, R. Television's Second Golden Age. Nueva York: Syracuse University Press, 1997. 